\title{
Preparation and Properties of Charged Copolypeptide Membranes as Biodegradable Materials
}

\author{
Toshio HaYASHI, ${ }^{*}$ Eiji NAKANISHI, ${ }^{* *}$ and Akio NAKAJIMA*** \\ * Research Center for Medical Polymers and Biomaterials, Kyoto University, \\ Sakyo-ku, Kyoto 606, Japan \\ ** Department of Material Science, Nagoya Institute of Technology, \\ Showa-ku, Nagoya 466, Japan \\ *** Department of Applied Chemistry, Osaka Institute of Technology, \\ Asahi-ku, Osaka 535, Japan
}

(Received March 9, 1987)

\begin{abstract}
Three component random copolypeptides consisting of $\mathrm{N}$-hydroxyalkyl Lglutamine, L-glutamic acid, and L-lysine were prepared by carrying out aminolysis reactions with aminoalcohols, such as 3-amino-1-propanol (P) or 5-amino-1-pentanol (Pe), followed by crosslinking reaction with octamethylenediamine (OMDA) on starting polymer membranes consisting of $\gamma$ methyl-L-glutamate (M), L-glutamic acid (B), and L-lysine (K). The effective crosslink density was shown to be proportional to the content of the crosslinker (OMDA) in the reaction mixture. The tensile properties of these hydrophilic membranes were highly dependent on the degree of swelling in the pseudo-extracellular fluid (PECF), hydrophobicity of the side chains, and the effective charge density of membranes, and their behavior was typical of an elastomer. A higher rate of water permeability was obtained with charged membranes than non-charged and/or compensated charged membranes with the same order of the degree of swelling in PECF. Biodegradation of the samples in vitro by pronase $\mathrm{E}$ and papain indicated that the degradation could be regarded as a bulk rather than a surface phenomenon. The rate of degradation was also highly dependent on the degree of swelling of membranes, as well as on the hydrophobicity and effective charge density of side chains of the samples.
\end{abstract}

KEY WORDS Hydrophilic Copolypeptide / Charged Membrane / Degree of Swelling / Water Vapor Permeability / Tensile Property / Enzymatic Degradation in Vitro / Pronase E / Papain /

Poly ( $\alpha$-amino acid)s and their copolymers are very useful for biodegradable medical applications such as temporary artificical skin substitutes in burn therapy, temporary barriers to prevent adhesion between natural tissues planes damaged eigher by accident or surgery between the pericardium and heart wall during open-heart surgery, polymer carriers for conjugates coupled to proteins for therapeutic use and drug delivery systems. ${ }^{1}$ On the other hand, proteins contain both anionic and cationic groups in their molecules. Thus, it is interesting to investigate confirmations as well as membrane properties of copolypeptides carry- ing both negative and positive charges in the side chains of the same molecules from the standpoints of basic and applicable considerations.

In this paper, we prepared three component random copolypeptides (MBK) consisting of L-glutamic acid (B), L-lysine (K), and $N$ hydroxyalkyl-L-glutamine (M), as well as the corresponding two component random copolypeptides, copoly $(N$-hydroxypropyl-Lglutamine/L-glutamic acid) (MB) and copoly $(N$-hydroxypropyl-L-glutamine/L-lysine) (MK), and homopolymers, such as poly(L-glutamic acid) (PGlu), poly(L-lysine) (PL- 
Lys), and poly( $N$-hydroxyalkyl-L-glutamine) (PHPG and PHPeG), and investigated the relation between their bulk structures and membranes properties, such as the degree of swelling in the pseudo-extracellular fluid (PECF), tensile properties in PECF, water vapor permeability, and enzymatic degradation behavior in vitro of the hydrophilic membranes in PECF from an applicable point of view for biomedical materials.

\section{EXPERIMENTAL}

\section{Materials}

Synthesis of Copolypeptides. Three component random copolypeptide, $\operatorname{copoly}(\gamma-$ methyl-L-glutamate/ $\gamma$-benzyl-L-glutamate $/ \varepsilon-N$ carbobenzyloxy-L-lysine) (MBK), related two component random copolypeptides, $\operatorname{copoly}(\gamma-$ methyl-L-glutamate $/ \gamma$-benzyl-L-glu tamates (MB) and $\operatorname{copoly}(\gamma$-methyl-L-glutamate $/ \varepsilon-N$ carbobenzyloxy-L-lysine) (MK), and the corresponding homopolymers, $\operatorname{poly}(\gamma$-methyl-Lglutamate) (PMLG), poly( $\gamma$-benzyl-L-glutamate) (PBLG), and poly $(\varepsilon-N$-carbobenzyloxy-L-lysine) (PCBL) were synthesized by the $N$-carboxyanhydride (NCA) method. The monomers, M-NCA, B-NCA, and K-NCA, were prepared according to the method reported in the previous paper, ${ }^{2}$ and purified by recrystallization from an ethyl acetate solution with the addition of petroleum ether. Recrystallization was repeated more than three times. The polymerization was initiated with triethylamine (TEA) at an NCAto-TEA molar ratio of 50. All starting polymers were purified and fractionated as described in the previous paper. ${ }^{3}$ The results of all the polymerization are summarized in Table I.

Preparation of Hydrophilic Polymer Membranes. The debenzylation of $\gamma$-BLG as well as the decarbobenzylation of $\varepsilon-\mathrm{CBL}$ residues in copolymers was performed by anhydrous $\mathrm{HBr}$ treatment according to the method of Idelson and Blout. ${ }^{4}$ After a membrane of $c a$.
Table I. Copolymerization of random copolypeptides

\begin{tabular}{|c|c|c|c|c|c|}
\hline \multirow{2}{*}{$\begin{array}{l}\text { Sample } \\
\text { code }\end{array}$} & \multicolumn{3}{|c|}{$\mathrm{NCA} / \mathrm{mol}^{\circ} \%$} & \multirow{2}{*}{$\begin{array}{c}{[\eta] / \mathrm{dl} \mathrm{g}^{-1}} \\
\left(\mathrm{DCA}, 25^{\circ} \mathrm{C}\right)\end{array}$} & \multirow{2}{*}{$\bar{M}_{w}$} \\
\hline & $\mathbf{M}$ & B & $\mathrm{K}$ & & \\
\hline MBK-11 & 90 & 5 & 5 & 1.69 & 323,000 \\
\hline MBK-21 & 80 & 15 & 5 & 1.44 & 252,000 \\
\hline MBK-22 & 80 & 10 & 10 & 1.56 & 281,000 \\
\hline MBK-23 & 80 & 5 & 15 & 1.89 & 367,000 \\
\hline MBK-31 & 70 & 20 & 10 & 1.25 & 184,000 \\
\hline MBK-32 & 70 & 15 & 15 & 1.44 & 248,000 \\
\hline MBK-33 & 70 & 10 & 20 & 1.45 & 246,000 \\
\hline MB-1 & 90 & 10 & 0 & 2,01 & 375,000 \\
\hline MB-2 & 80 & 20 & 0 & 1.98 & 371,000 \\
\hline MK-1 & 90 & 0 & 10 & 1.55 & 276,000 \\
\hline MK-2 & 80 & 0 & 20 & 1.26 & 176,000 \\
\hline PMLG-1 & 100 & 0 & 0 & 0.98 & 163,000 \\
\hline PBLG-1 & 0 & 100 & 0 & 1.22 & 224,000 \\
\hline PCBL-1 & 0 & 0 & 100 & 1.88 & 312,000 \\
\hline
\end{tabular}

$$
M \quad B \quad K
$$
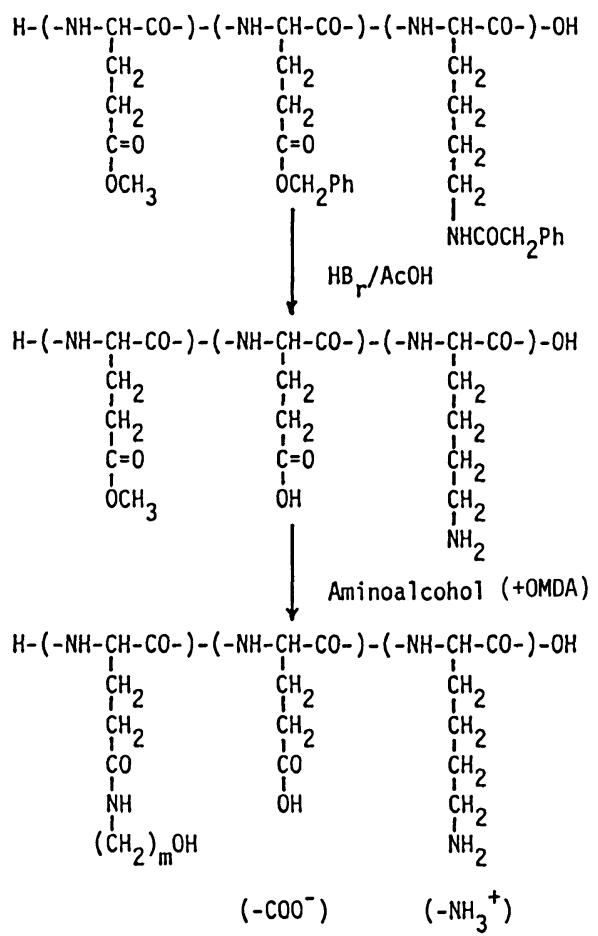

Figure 1. Schematic diagrams of the preparation of hydrophilic membranes.

$100 \mu \mathrm{m}$ in thickness cast from an appropriate solvent was immersed in the mixture of 3amino-1-propanol (P) and the crosslinker, 1,8- 
octamethylenediamine (OMDA), as well as the mixture of 5-amino-1-pentanol (Pe), 1-pentanol, and OMDA, at 58 to $62^{\circ} \mathrm{C}$ for $48 \mathrm{~h}$, the membrane was washed with pure water, ethyl ether, and stored in ethanol. Figure 1 denotes a schematic diagrams of the preparation of the hydrophilic membranes.

\section{Measurements}

Molecular Characterizations of the Starting Copolymers. The molecular weights of the starting polymers were determined in $N, N^{\prime}$ dimethylformamide (DMF) or $m$-cresol at $25.0^{\circ} \mathrm{C}$ by sedimentation equilibrium using a MOM Type-3170-b ultracentrifuge equipped with a Reyleigh interference optical system and a $12 \mathrm{~mm}$ double sector cell. ${ }^{5}$ The viscosity numbers were also obtained in a dichloroacetic acid (DCA) solution, using an Ubbelohde type viscometer at $25.0^{\circ} \mathrm{C}$. These data are listed in Table I.

The chain conformation of the hydrophilic polymers in PECF was examined by optical rotatory dispersion (ORD) measurements. The Moffitt-Yang parameter $b_{0}$ was evaluated from the ORD data obtained with a Yanagimoto OR-100 Type spectrophotometer, using a tungsten lamp at $37.0^{\circ} \mathrm{C}$. Table II summarizes the experimental data of $b_{0}$ for $\operatorname{MBK}(\mathrm{P}), \operatorname{MB}(\mathrm{P}), \mathrm{MK}(\mathrm{P}), \mathrm{PHPG}, \mathrm{PLGlu}$, and PLLys in PECF at $\mathrm{pH}=7.4$ and $37.0^{\circ} \mathrm{C}$.

Physical Properties of Hydrophilic Mem-

Table II. Moffitt parameter $b_{0}$ of samples in PECF $\left(\mathrm{pH}=7.4,37^{\circ} \mathrm{C}\right)$

\begin{tabular}{llr}
\hline Sample code & Starting polymer & \multicolumn{1}{c}{$b_{0}$} \\
\hline MBK(P)-110 & MBK-11 & -150 \\
MBK(P)-220 & MBK-22 & -140 \\
MBK(P)-310 & MBK-31 & -90 \\
MBK(P)-320 & MBK-32 & -120 \\
MBK(P)-330 & MBK-33 & -110 \\
MB(P)-20 & MB-2 & -60 \\
MK(P)-20 & MK-2 & -100 \\
PHPG-10 & PMLG-1 & -150 \\
PLGlu-10 & PBLG-1 & 60 \\
PLLys-10 & PCBL-1 & 40 \\
\hline
\end{tabular}

branes. The degree of swelling $Q_{\mathrm{w}}(\%)$ in PECF was determined by equilibrating the membrane in PECF solution at $37.0^{\circ} \mathrm{C}$. The membrane was removed, blotted to remove surface PECF and weighed until a constant weight was achieved. The membrane was then dried in a vacuum oven. The $Q_{w}(\%)$ was defined as the ratio of the amount of PECF to weight of the dried crosslinked hydrophilic membrane.

The tensile properties of hydrophilic membranes were measured by a Tensilon UTM-II20 (Toyo-Boldwin Co.) using the standard techniques in PECF at $25.0^{\circ} \mathrm{C}$. All the samples were tested at an elongation rate of $40 \%$ per minute.

Water vapor permeation through the membranes was measured with a cylindical glass cell $^{6}$ at $37.0^{\circ} \mathrm{C}$. The exposed membrane area was $12.57 \mathrm{~cm}^{2}$.

Biodegradation of Hydrophilic Membranes in Vitro. Enzymatic degradation studies in vitro were carried out by using papain and pronase E. These enzymes were purchased from Nakarai Chem. Co. Enzyme solutions were prepared by standard techniques ${ }^{7}$ at $37.0^{\circ} \mathrm{C}$. A series of the crosslinked hydrophilic membranes were exposed to PECF solution at $\mathrm{pH}=7.4$ with appropriate activators at $37.0^{\circ} \mathrm{C}$. Polymer membranes were removed from the enzyme solution at appropriate time intervals, weighed, and then vacuum dried at $60^{\circ} \mathrm{C}$ to constant weights.

\section{RESULTS AND DISCUSSION}

\section{Molecular Conformations of Copolymers in PECF}

In Table II, it is shown that PHPG homopolymer exists in the interrupted $\alpha$-helix conformation at $\mathrm{pH}=7.4$ and $37.0^{\circ} \mathrm{C}$ in $\mathrm{PECF}$, while PLGlu and PLLys homopolymers exist in charged coil conformation. ${ }^{8}$

The equimolar-charged hydrophilic membranes, $\operatorname{MBK}(\mathrm{P})-100, \quad \mathrm{MBK}(\mathrm{P})-220$, and $\operatorname{MBK}(\mathrm{P})-320$, exist in the interrupted $\alpha$-helix 
conformation whose molar contents were almost of the same order as that of the PHPG homopolymer, indicating that the interaction between $B$ and $K$ residues leads to helix stabilization. ${ }^{9}$

\section{Degree of Swelling of Hydrophilic Membranes in PECF}

The degree of swelling in a solvent is determined by the interaction energy between the solvent molecules and polymer segments as well as the elastic energy (crosslink density) for a solvent-swollen polymer.

On the other hand, the precise crosslink density has not been determined because of the uncertainty in the relative reactivities of 3amino-1-propanol or 5-amino-1-pentanol and OMDA, and also because estimation of the fraction of the reacted diamine molecules which form effective crosslinks is difficult. The effect of crosslinker (OMDA) concentration in the reaction on the degree of swelling of the crosslinked membranes in PECF is shown in

Table III. Preparative data of hydrophilic sample membranes

\begin{tabular}{|c|c|c|c|}
\hline \multirow{2}{*}{$\begin{array}{c}\text { Sample } \\
\text { code }\end{array}$} & \multirow{2}{*}{$\begin{array}{l}\text { Starting } \\
\text { polymer }\end{array}$} & \multirow{2}{*}{$\frac{\mathrm{OMDA}}{\mathrm{mol} \%}$} & \multirow{2}{*}{$\frac{Q_{\mathrm{w}}}{\%}$} \\
\hline & & & \\
\hline $\mathrm{MB}(\mathrm{P})-21$ & MB-2 & 1.0 & 1980 \\
\hline $\mathrm{MB}(\mathrm{P})-22$ & & 2.0 & 1260 \\
\hline $\mathrm{MB}(\mathrm{P})-23$ & & 3.0 & 1010 \\
\hline $\mathrm{MB}(\mathrm{P})-24$ & & 4.0 & 810 \\
\hline MBK(P)-221 & MBK-22 & 1.0 & 1400 \\
\hline MBK(P)-222 & & 2.0 & 970 \\
\hline MBK(P)-223 & & 3.0 & 760 \\
\hline MBK(P)-224 & & 4.0 & 650 \\
\hline PHPG-11 & PMLG-1 & 1.0 & 1180 \\
\hline PHPG-12 & & 2.0 & 810 \\
\hline PHPG-13 & & 3.0 & 590 \\
\hline PHPG-14 & & 4.0 & 490 \\
\hline $\operatorname{MBK}(\mathrm{Pe})-221$ & MBK-22 & 1.0 & 460 \\
\hline MBK(Pe)-222 & & 2.0 & 310 \\
\hline $\mathrm{MBK}(\mathrm{Pe})-223$ & & 3.0 & 230 \\
\hline PHPeG-11 & PMLG-1 & 1.0 & 360 \\
\hline PHPeG-12 & & 2.0 & 240 \\
\hline PHPeG-13 & & 3.0 & 185 \\
\hline
\end{tabular}

Figure 2. The degree of swelling in PECF decreases with increasing OMDA molar concentration in the reaction solution.

When the degree of swelling is quite large, it is given by the following equation according to rubber elasticity theory ${ }^{10}$

$$
Q_{\mathrm{w}}^{5 / 3}=\left(\bar{v} M_{c}\right)\left(1-2 M_{c} / M\right)^{-1}\left(1 / 2-\chi_{1}\right) / V_{1}
$$

where $M_{c}$ is the molecular weight per crosslinked unit, $M$ the primary molecular weight, $\bar{v}$ the specific volume of polymer, $V_{1}$ the molar volume of solvent and $\chi_{1}$ the interaction parameter. The factor $\left(1-2 M_{\mathrm{c}} / M\right)$ expresses the correction for network inperfections resulting from chain ends. For a quite high molecular weight polymer chain, it reduces to unity. As the effective crosslink density, $f_{c}$ is proportional to the value of $M_{o} / M_{c}$ where $M_{o}$ is the molecular weight of the repeat unit (monomeric unit), equation 1 may be simplified as

$$
Q_{\mathrm{w}}^{5 / 3}=\left(v M_{o}\right)\left(1 / 2-\chi_{1}\right) 1 / V_{l} f_{c}
$$

The slope of $\log -\log$ plots in Figure 2 has the value of $-3 / 5$ as predicted by eq 2 . The effective crosslink density $f_{c}$ is proportional to the crosslinker OMDA concentration $\left(\mathrm{mol}_{\mathrm{o}}^{\mathrm{o}}\right)$ in the reaction solution. The $Q_{\mathrm{w}}$ values ob-

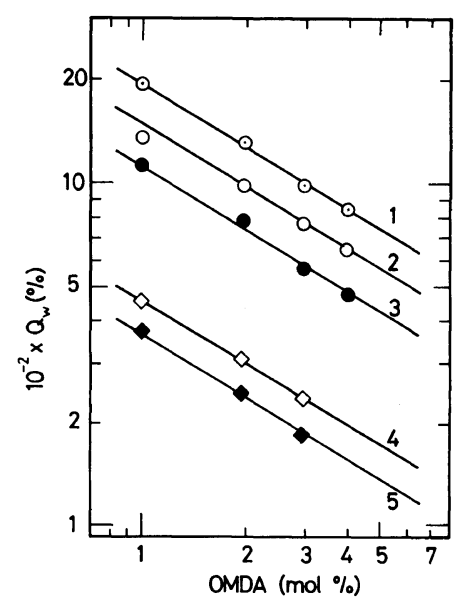

Figure 2. Degree of swelling $Q_{\mathrm{w}}(\%)$ of hydrophilic membranes in PECF as a function of the molar percent

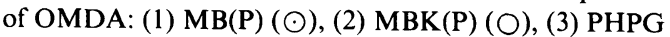
$(\bigcirc),(4) \operatorname{MBK}(\mathrm{Pe})(\diamond)$, and (5) PHPeG $(\diamond)$. 
tained with $\mathrm{MB}(\mathrm{P})$ charged membranes were higher than those obtained with the compensated-charged membranes, $\operatorname{MBK}(\mathrm{P})$, as well as the non-charged membranes, PHPG of same order of OMDA molar concentration, indicating that $Q_{\mathrm{w}}$ value depends on the charge density in membranes.

\section{Tensile Properties of Hydrophilic Membranes in PECF}

The tensile properties of hydrophilic membranes are highly dependent on the degree of swelling in PECF. Further, elastomeric mem-

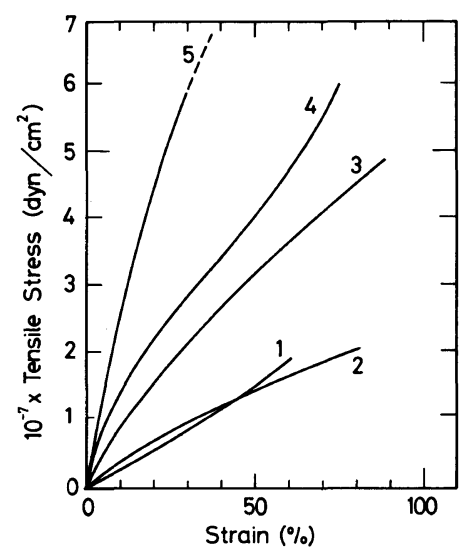

Figure 3. Stress-strain properties of membranes in PECF at $25^{\circ} \mathrm{C}$ for: (1) MB(P)-24, (2) PHPG-12, (3) MBK(P)-222, (4) PHPeG-11, and (5) MBK(Pe)-221.

Table IV. Mechanical properties of membranes in PECF, $25^{\circ} \mathrm{C}$

\begin{tabular}{|c|c|c|c|c|}
\hline \multirow{2}{*}{$\begin{array}{l}\text { Sample } \\
\text { code }\end{array}$} & $Q_{\mathrm{w}}$ & $E$ & $\sigma_{\mathrm{B}}$ & $\varepsilon_{\mathrm{B}}$ \\
\hline & $\%$ & dyn $\mathrm{cm}^{-2}$ & dyn $\mathrm{cm}^{-2}$ & $\%$ \\
\hline $\mathrm{MB}(\mathrm{P})-22$ & 1260 & $2.0 \times 10^{7}$ & $1.2 \times 10^{7}$ & 45 \\
\hline $\mathrm{MB}(\mathrm{P})-24$ & 810 & $2.8 \times 10^{7}$ & $1.9 \times 10^{7}$ & 60 \\
\hline PHPG-12 & 810 & $4.0 \times 10^{7}$ & $2.1 \times 10^{7}$ & 82 \\
\hline PHPG-13 & 590 & $8.7 \times 10^{7}$ & $4.6 \times 10^{7}$ & 75 \\
\hline $\operatorname{MBK}(\mathrm{P})-222$ & 970 & $8.8 \times 10^{7}$ & $4.9 \times 10^{7}$ & 88 \\
\hline MBK(P)-224 & 650 & $1.4 \times 10^{8}$ & $6.5 \times 10^{7}$ & 90 \\
\hline PHPeG-11 & 360 & $4.2 \times 10^{8}$ & $6.0 \times 10^{7}$ & 75 \\
\hline PHPeG-12 & 240 & $7.8 \times 10^{8}$ & $9.7 \times 10^{7}$ & 80 \\
\hline $\operatorname{MBK}(\mathrm{Pe})-221$ & 460 & $8.0 \times 10^{8}$ & $3.6 \times 10^{8}$ & 95 \\
\hline $\operatorname{MBK}(\mathrm{Pe})-222$ & 310 & $1.2 \times 10^{9}$ & $5.8 \times 10^{8}$ & 90 \\
\hline
\end{tabular}

branes are highly suited to biomedical applications, such as membranes for artificial organs, reconstructive prosthesis, and cosmesis.

Figure 3 illustrates the stress-strain curves of hydrophilic membranes in PECF at $25^{\circ} \mathrm{C}$. While MB(P)-24 and PHPG membranes gave lower strength, $\mathrm{MBK}(\mathrm{P})-222$ attained higher strength with a moderate modulus. Table IV lists the experimental findings of Young's modulus $E$ at an elongation of $1 \%$, the tensile strength $\sigma_{\mathrm{B}}$ and elongation $\varepsilon_{\mathrm{B}}$ at the breakage point with $Q_{\mathrm{w}}(\%)$ values for membranes in PECF. Tensile properties of $\operatorname{MBK}(\mathrm{P})-222$ and $\mathrm{MBK}(\mathrm{Pe})-221$ membranes were more than PHPG-12, MB(P)-24, and PHPeG-11, respectively, even when the $Q_{\mathrm{w}}$ values of $\operatorname{MBK}(\mathrm{P})$ 222 and $\mathrm{MBK}(\mathrm{Pe})-221$, the compensatedcharged membranes, were more than the corresponding non-charged membranes, PHPG12 and PHPeG-11, and $\mathrm{MB}(\mathrm{P})-24$ charged membrane, showing charge interactions between cation and anions in the molecular chains to affect the tensile strength of the membranes. Further, it is pointed out that the degree of swelling in PECF for membranes containing $N$-hydroxypentyl-L-glutamine (Pe) becomes much lower than those for membranes containing $N$-hydroxypropyl-Lglutamine (P) (Table III). The hydrophobic nature of glutamine side chain increases from $\mathrm{P}$ to Pe. Lotan, et al. ${ }^{11}$ have shown that the helical content increases with increasing length of hydrocarbon of side chain in aqueous solution, and that PHPeG exists almost completely in the $\alpha$-helix conformation, while PHPG exists in the interrupted $\alpha$-helix conformation. Thus, the $Q_{\mathrm{w}}$ value may be affected by molecular conformation.

Furthermore, it is pointed out from Figure 3 and Table IV that the hydrophobic nature of the glutamine side chain affected the mechanical properties of membranes..

\section{Water Vapor Permeability of Membranes}

A large variety of synthetic polymer membranes has been investigated in the treatment 
of burns. ${ }^{12-14}$ Among them, for example, the formulation of a crosslinked polymer in the form of hydrogel appears to have added capability for encouraging cellular migration into the graft and vascularization. ${ }^{15}$ In designing an effective wound closure or an artificial skin inner-layer substitute, at least two functions of skin are urgently essential for survival. The first is the ability of skin to keep most bacteria out. The second is its ability to control water passage moderately from tissue and organ. Thus, it is important to know the value of the rate of water vapor permeability $V_{\mathrm{f}}\left(\mathrm{g} \mathrm{m}^{-2}\right.$ day) through the membrane. If the $V_{\mathrm{f}}$ value is excessively low, water accumulates at the interface between the woundbed and impermeable graft, and edema results. The graftwoundbed interfacial contact is thereby undermined. As a result, maintain the ability to wet the woundbed and thereby maintain an airfree interface, an inner skin substitute membrane should have a higher $V_{\mathrm{f}}$ value than that of the human physiological level of about $V_{\mathrm{f}}=$ 500 ( $\mathrm{g} \mathrm{m}^{-2}$ day).

Figure 4 illustrates the relation between the rate of water vapor permeability $V_{\mathrm{f}}\left(\mathrm{g} \mathrm{m}^{-2}\right.$ day) of PECF and the degree of swelling $Q_{\mathrm{w}}$ $(\%)$ for membranes at $37.0^{\circ} \mathrm{C}$. It may be also shown that the $V_{\mathrm{f}}$ value is highly dependent on

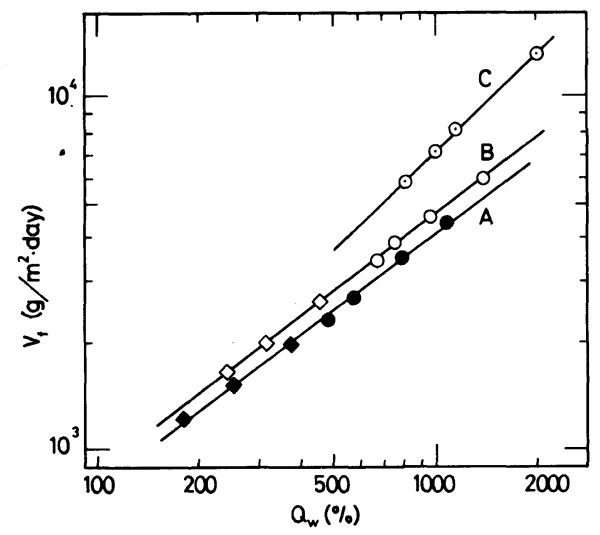

Figure 4. Rate of water vapor permeability $V_{\mathrm{f}}\left(\mathrm{g} \mathrm{m}^{-2}\right.$ day) as a function of the degree of swelling $Q_{\mathrm{w}}(\%)$ for membranes: (A)PHPG (O) and PHPeG ( $\bullet)$, (B) $\operatorname{MBK}(\mathrm{P})(\bigcirc)$ and $\operatorname{MBK}(\mathrm{Pe})(\diamond)$, and $(\mathrm{C}) \operatorname{MB}(\mathrm{P})(\odot)$. the $Q_{\mathrm{w}}$ value in PECF. Further, it may be judged in Figure 4 that the $V_{\mathrm{f}}$ value of the charged membranes, $\mathrm{MB}(\mathrm{P})$, is more than those of the compensated-charged or noncharged membranes, $\operatorname{MBK}(\mathrm{P}), \operatorname{MBK}(\mathrm{Pe})$, PHPG, or PHPeG, at the same value of $Q_{w}$, indicating that the charge density in membranes affects the state of water in membranes.

\section{Biodegradation of Membranes in Vitro}

Numerous proteases may be present at a wound site. ${ }^{16}$ These proteases are divided into some classes depending on the structure of active sites. Enzymes of inflammatory response that are likely to degrade $\operatorname{poly}(\alpha$-amino acid)s include the endopeptidase Cathepsin B and the exopeptidases Carboxypeptidase and Leucine amino peptidase. ${ }^{17}$ In the present investigation, the plant thiol endopeptidase Papain was selected as a commercially available analog of Cathepsin B as well as Pronase $\mathrm{E}$ as a commercially available analog of an exopeptidase released during the acute and chronic stages of the inflammatory response. Although Papain is a general plant thiol endopeptidase, it has preference for peptide bonds where the amino acid residue of the carbonyl group is arginine, lysine, or glutamine and where this amino acid is joined on either side by amino acids with hydrophobic side chains. ${ }^{18}$ Pronase E obtained from Streptomyces griseus has been separated into eight proteases $^{19}$ of which four are serine endopeptidases. ${ }^{20}$ These endopeptidases are not expected to hydrolyze $N$-hydroxyalkyl-Lglutamine series. The remaining four pronase enzymes are exopeptidases; two are aminopeptidases $^{21}$ and two are carboxypeptidases. ${ }^{22}$ The pronase $\mathrm{E}$ activity observed in the crosslinked membranes in this study almost certainly comes from these exopeptidases.

Pre-weighed MBK(P)-224 membranes were exposed to Pronase E or Papain and the results are illustrated in Figure 5. The dry weights of the membranes began to decrease immediately and the weight loss continued steadily thereaf- 


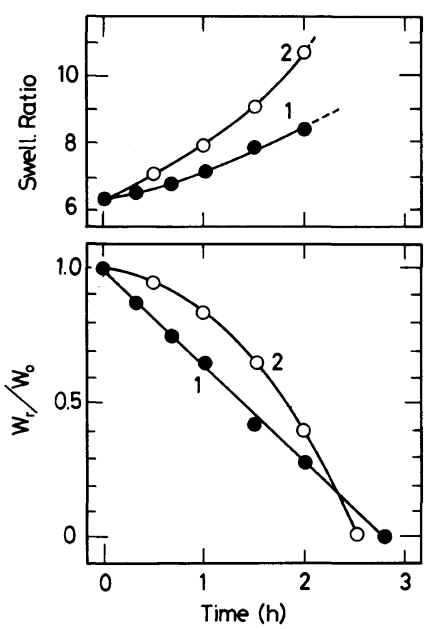

Figure 5. Dry weight ratio $\left(W_{\mathrm{r}} / W_{\mathrm{o}}\right)$ and swelling ratio of PECF for MBK(P)-224 membrane as a function of enzymatic digestion time (hr) with: (1) Pronase E (O) $\left(0.5 \mathrm{mg} \mathrm{ml}^{-1}\right)$ and (2) Papain (O) $\left(0.12 \mathrm{mg} \mathrm{ml}^{-1}\right)$ at $37.0^{\circ} \mathrm{C}$ and $\mathrm{pH}=7.4$.

ter for the Pronase E system. Simultaneously, the swelling ratio increased steadily. On the other hand, the MBK(P)-224 membrane that was exposed to Papain showed a lag time with respect to weight loss so that when the experiment was half over, i.e., at half the time needed to dissolve the specimen, about $70 \%$ of the dry weight remained. The increase in swelling ratio with the Papain system was always higher order than that with the Pronase E system. Judging from the immediate increase in the swelling ratio, the degradation of the MBK(P)224 membrane should be a bulk rather than a surface phenomenon. Qualitative differences in the action of Pronase E and Papain are clearly shown in Figure 5. The immediate and steady weight loss observed with the Pronase E system is consistent with the release of monomers from the chain ends by exopeptidases. On the other hand, an endopeptidase, such as Papain, must make two incisions in a chain segment to produce a soluble fragment, but a single cleavage will decrease the effective crosslink density, resulting in increased swelling ratios of membranes. Thus, the initial effect of Papain is therefore to decrease the effective

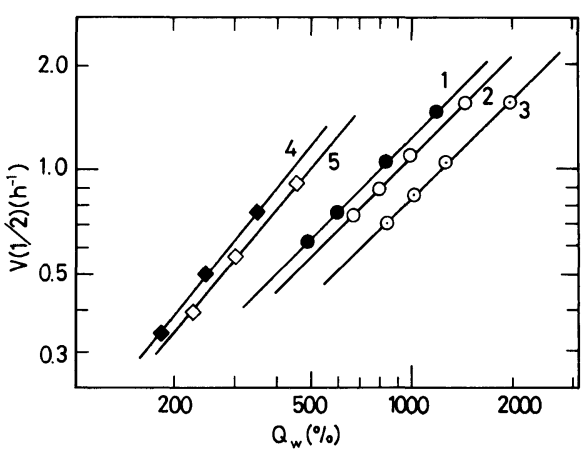

Figure 6. Rate of Pronase E digestion $V(1 / 2)\left(\mathrm{h}^{-1}\right)$ as a function of the degree of swelling $Q_{\mathrm{w}}(\%)$ for: (1) PHPG (๑), (2) $\operatorname{MBK}(\mathrm{P})(\bigcirc),(3) \mathrm{MB}(\mathrm{P})(\odot)$, (4) PHPeG (৫), and $(5) \operatorname{MBK}(\mathrm{Pe})(\diamond)$.

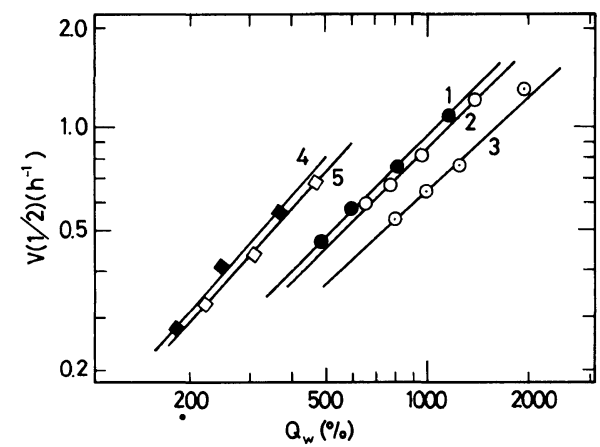

Figure 7. Rate of Papain digestion $V(1 / 2)\left(\mathrm{h}^{-1}\right)$ as a function of the degree of swelling $Q_{\mathrm{w}}(\%)$ for: (1) PHPG (๑), (2) $\operatorname{MBK}(\mathrm{P})(\bigcirc),(3) \mathrm{MB}(\mathrm{P})(\odot)$, (4) PHPeG (४), and $(5) \operatorname{MBK}(\mathrm{Pe})(\diamond)$.

crosslink density without producing soluble materials.

Figures 6 and 7 summarize the rates of Pronase E and Papain digestion $V(1 / 2)\left(\mathrm{h}^{-1}\right)$, respectively, as a function of the degree of swelling $Q_{\mathrm{w}}(\%)$ in PECF for hydrophilic polymer membranes. $V(1 / 2)$ is defined as the reciprocal of the time required for the sample weight to be reduced to one-half its initial value. It is clearly shown that the order of degradation rates among the hydrophilic membranes is as follows: $\mathrm{PHPeG}>\mathrm{MBK}(\mathrm{Pe})$ $>$ PHPG $>$ MBK(P) $>\mathrm{MB}(\mathrm{P})$ at the same order of $Q_{\mathrm{w}}(\%)$ for each membrane.

In conclusion, the effective crosslink density 
was shown to be proportional to the content of the crosslinker (OMDA) in the reaction mixture. $Q_{\mathrm{w}}$ values were highly dependent on the charge density in membranes. The tensile properties of these hydrophilic membranes depended on $Q_{\mathrm{w}}$ in PECF, charged interactions between cations and anions in the molecular chain, and the molecular conformation of chains in membranes, and their behavior was typical of an elastomer. Biodegradation of these hydrophilic membranes by Pronase E or Papain in vitro indicated that the degradation could be regarded as a bulk rather than a surface phenomenon. The rate of degradation of sample was also highly dependent on $Q_{\mathrm{w}}$ $(\%)$ of membranes, as well as on charge density of the sample side chains.

\section{REFERENCES}

1. J. M. Anderson, K. L. Spilizewski, and A. Hiltner, in "Biocompatibility of Tissue Analogs," D. F. Williams, Ed., CRC Press, N. W. Boca Raton, Florida, 1985, p 68.

2. T. Hayashi, E. Nakanishi, and A. Nakajima, Kobunshi Ronbunshu, 43, 633 (1986).

3. T. Hayashi, Y. Tabata, and A. Nakajima, Polym. J., 17, 463 (1985).

4. M. Idelson and E. R. Blout, J. Am. Chem. Soc., 80, 4631 (1958).
5. T. Hayashi, G. W. Chen, and A. Nakajima, Polym. J., 16, 739 (1984).

6. T. Hayashi, K. Takeshima, E. Kobataka, and A. Nakajima, Kobunshi Ronbunshu, 42, 777 (1985).

7. H. B. Bensusan, Biochemistry, 8, 4716 (1969).

8. M. Marcellet and C. Loucheux, Polymer, 16, 785 (1975).

9. P. Doty, K. Imahori, and E. Klemperer, Proc. Natl. Acad. Sci., U.S.A., 44, 424 (1958).

10. P. J. Flory, "Principles of Polymer Chemistry," Cornell Univ. Press, Ithaca, New York and London, 1953, p 576.

11. N. L. Lotan, A. Yaron, A. Berger, and M. Sela, Biopolymers, 3, 625 (1965).

12. J. Hubacek, K. Kliment, J. Dusek, and J. Hubacek, J. Biomed. Mater. Res., 1, 387 (1967).

13. I. R. Schmolka, J. Biomed. Mater. Res., 6, 571 (1972).

14. J. Guldalian, C. Jelenko, III, D. Calloway, and J. T. McKnight, J. Trauma, 13, 32 (1973).

15. I. V. Yannas and J. F. Burke, J. Biomed. Mater. Res., 14, 65 (1980).

16. D. F. Williams, J. Bioeng., 1, 279 (1977).

17. T. N. Salthouse, J. Biomed. Mater. Res., 10, 197 (1976).

18. J. Lowbridge and J. S. Fruton, J. Biol. Chem., 249, 6754 (1974).

19. B. Lofgvist and L. B. Sjoberg, Acta Chem. Scand., 25, 1663 (1971).

20. W. M. Awad, Jr., A. R. Soto, S. Siegel, W. E. Skiba, G. G. Bergstrom, and M. S. Ochoa, J. Biol. Chem., 247, 4144 (1972).

21. K. P. Vosbeck, K. F. Chow, and W. M. Ȧwad, Jr., J. Biol. Chem., 248, 6029 (1973).

22. B. Lofgvist, Acta Chem. Scand., B28, 1013 (1974). 